\title{
Identification of the Female-Produced Sex Pheromone of the Leafminer Holocacista capensis Infesting Grapevine in South Africa
}

\author{
Hong-Lei Wang ${ }^{1}$ • Henk Geertsema ${ }^{2}$ • Erik J. van Nieukerken ${ }^{3}$ • Christer Löfstedt ${ }^{1}$
}

Received: 21 April 2015 /Revised: 25 June 2015 / Accepted: 10 July 2015 / Published online: 14 August 2015

(C) The Author(s) 2015. This article is published with open access at Springerlink.com

\begin{abstract}
We report the first identification of a sex pheromone in a heliozelid moth, Holocacista capensis van Nieukerken \& Geertsema. This leafminer recently infested grapevine in South Africa. Compared to solvent extraction of pheromone glands, solid phase microextraction (SPME) proved to be highly effective for collection of the pheromone from calling females. The volatiles collected by SPME were analyzed by gas chromatography with electroantennographic detection (GC/EAD). Three compounds eliciting electrophysiological activity from the male antenna were identified as (Z)-5-tetradecenal, (Z)-7tetradecenal, and $(Z)-9$-hexadecenal by coupled gas chromatography-mass spectrometry (GC/MS). GC/MS analysis of dimethyldisulphide (DMDS) derivatives of fatty acyl moieties in pheromone gland extracts confirmed the presence of the corresponding putative pheromone precursors with double bonds in the same position and with $Z$ geometry. Field trapping experiments in a South African vineyard confirmed that both (Z)-5-tetradecenal and (Z)-7tetradecenal are essential for the attraction of male $H$. capensis, whereas addition of (Z)-9-hexadecenal to the blend did not affect the attractiveness. The composition of the pheromone is discussed in relation to the phylogeny of this family of moths.
\end{abstract}

Hong-Lei Wang

hong-lei.wang@biol.lu.se

1 Department of Biology, Lund University, SE-223 62 Lund, Sweden

2 Department of Conservation Ecology and Entomology, Stellenbosch University, Stellenbosch, South Africa

3 Naturalis Biodiversity Center, Leiden, The Netherlands
Keywords Sex pheromone $\cdot$ Leafminer $\cdot$ Heliozelidae . Holocacista capensis · Primitive moth · Vineyard pest · Vitis vinifera $\cdot(Z)-5$-tetradecenal $\cdot(Z)$-7-tetradecenal $\cdot$ Lepidoptera

\section{Introduction}

Leafmining Lepidoptera, such as the globally problematic citrus leafminer Phyllocnistis citrella Stainton (Gracillariidae) (Heppner and Dixon 1995), and species of the genus Phyllonorycter that attack apple (Maier 2001; Minarro and Jacas 2011) constitute serious economic problems. Leafminers or sometimes gall-makers, particularly those from the poorly-studied Heliozelidae family, can cause damage on host plants belonging to the grape family Vitaceae. This may affect the grape and subsequent production of wine and raisins (Alma 1995; Duso et al. 2011; van Nieukerken et al. 2012; Ueno et al. 1987).

In recent years, a heliozelid leafminer has sometimes occurred in high densities in the table grape growing area near Paarl (Western Cape, South Africa), where the presence of this insect is of concern in relation to export of table grapes. Recently, this leafminer, considered to be a native South African species, has been described as the new species Holocacista capensis van Nieukerken \& Geertsema. This species probably shifted hosts from native Rhoicissus species (Vitaceae) onto the introduced grapevine (van Nieukerken and Geertsema 2015). The moth, which is only about 1.5 to $2 \mathrm{~mm}$ long, occurs in several generations throughout the growing season, including the late summer when the grapes are harvested.

To protect grapevines against insect infestation, various pesticides have been used over the past decades with the result that pesticide residues may contaminate the grapes and are eventually carried through into the wine (Andrey and Amstutz 
2000; Cabras et al. 1995). The use of pesticides is not recommended, especially in the period around harvest when the leafminer may be highly abundant. In this case, the table grape industry would particularly benefit from other environmentally safe and sustainable ways for control of vineyard pests, and the use of insect pheromones might be a good alternative.

Rigorously identified sex pheromones have so far not been reported in the moth family Heliozelidae, but, in a field screening test in Hungary, male adults of Antispila treitschkiella (Fischer von Röslerstamm) were recorded in traps baited with (Z)-7-tetradecenal (Z7-14:Ald) (Tóth et al. 1992). This group of moths has not been recognized to contain important pests until recently (Bernardo et al. 2015; van Nieukerken et al. 2012), and consequently, there was no particular incentive to identify their pheromones. Furthermore, collection and isolation of volatiles from these very tiny moths is a challenge, although previous studies in some small leafminers such as the Phyllonorycter species have been successful, using the solid phase microextraction technique (SPME) (Borg-Karlson and Mozûraitis 1996).

From a phylogenetic point of view, the structures of the heliozelid sex pheromones are of great interest, because Heliozelidae belongs to Adeloidea, one of the Lepidopteran superfamilies that is not classified to the large clade Ditrysia, but to earlier diverging Lepidoptera. There is a diversity of pheromone structures reported from the few non-ditrysian families where pheromones have been studied, including the Eriocraniidae (Kozlov et al. 1996; Zhu et al. 1995), Nepticulidae (Tóth et al. 1995), Prodoxidae (Löfstedt et al. 2004), and Tischeriidae (Molnár et al. 2012). Here, we report identification of the first heliozelid sex pheromone, that of the grape leafminer, $H$. capensis.

\section{Methods and Materials}

Insects Larvae of the summer generation of $H$. capensis were collected in table grape plantations of the cultivars "Regal" and "Red Globe", North-West of Paarl, (33 $\left.43^{\circ} \mathrm{S}, 18^{\circ} 57^{\prime} \mathrm{E}\right)$, Western Cape, South Africa, on 25 January 2013 (disclaimer: the sampled farm was not particularly more affected than any nearby estate, whether table grape or wine farm). Leafmines were kept with pieces of the leaf in small plastic containers. After the larvae prepared a cocoon and left the mine, 50 individual cocoons were each placed in a small glass tube $(10 \mathrm{x}$ $1 \mathrm{~cm}$ i.d.) and sent to Lund where they were stored at $23{ }^{\circ} \mathrm{C}$, $60 \%$ R.H. and 18:6 h L:D cycle. Moths (21 females and 11 males) emerged between 9 and 15 February. Newly emerged moths were separated in individual vials (preventing mating) and sexed based on the difference in relative length of antenna. The adults were kept individually until used in experiments.
Chemicals Reference compounds of different origin and purity were available for the identification work from our laboratory collection of pheromone compounds. For chemical identification and electrophysiological experiments, $(Z)-5$ tetradecenal (Z5-14:Ald), (E)-5-tetradecenal (E5-14:Ald), (Z)-7-tetradecenal (Z7-14:Ald), and (E)-7-tetradecenal (E714:Ald) were prepared by oxidation of corresponding alcohols with pyridinium chlorochromate as described by Corey and Suggs (1975). The corresponding fatty acids and their methyl esters also were prepared from the respective alcohols as described in Wang et al. (2010). Z5-14:Ald (chemical purity 99.6 \%), Z7-14:Ald (chemical purity $98.2 \%$ ), and (Z)-9hexadecenal (Z9-16:Ald, chemical purity $99.0 \%$ ) used for field experiments were purchased from Pherobank (Wageningen, The Netherlands).

Sex Pheromone Collection SPME samples were collected from 1 to $7 \mathrm{~d}$-old virgin female adults. Thus, 7-9 virgin females were put in a $5 \mathrm{ml}$ gas tight syringe (Hamilton, Switzerland) into which a fiber coated with PMDS (7 $\mu \mathrm{m}$ film thickness, Supelco, USA) was inserted. Headspace volatiles were collected from the same batch of females for the first $6 \mathrm{hr}$ (scotophase), the next $12 \mathrm{hr}$ (photophase), the next $24 \mathrm{hr}$, and a final $48 \mathrm{hr}$. The SPME samples were subjected immediately to GC/MS or GC/EAD analysis.

In parallel to the SPME collection, batches of female abdominal tips, where the pheromone gland is assumed to be located, were dissected from virgin females up to $2 \mathrm{~d}$-old during three different periods, i.e., 2-4 hr into scotophase, $1 \mathrm{hr}$ before scotophase, and $1 \mathrm{hr}$ before photophase. Either a single abdominal tip or up to nine combined tips were extracted with $10 \mu \mathrm{l}$ of redistilled hexane and either analyzed by $\mathrm{GC} /$ MS or used for the GC/EAD assay.

The fatty acyl pheromone precursors in the abdominal tip residuals were subsequently extracted in $10 \mu \mathrm{l}$ chloroform/ methanol $(2: 1 \mathrm{v}: \mathrm{v})$ at room temperature for $24 \mathrm{hr}$, and then analyzed by GC/MS as corresponding methyl esters after basic methanolysis as described in Bjostad and Roelofs (1984).

Electrophysiology An Agilent 7890 gas chromatograph equipped with an HP-INNOWax column $(30 \mathrm{~m} \times 0.25 \mathrm{~mm}$ i.d., and $0.25 \mu \mathrm{m}$ film thickness; J\&W Scientific, USA) and a flame ionization detector (FID), as well as an electroantennographic detector (EAD) was used to identify physiologically active compounds in female pheromone extracts. The GC inlet was set at $230^{\circ} \mathrm{C}$, and a split of the carrier gas (hydrogen) at the end of the column allowed a 1:1 division of the GC effluent between the FID and EAD. After cutting off the tips, the antennae together with the head of 1-2-d-old male adults were mounted to a PRG-2 EAG (10x gain) probe (Syntech, Kirchzarten, Germany) using conductive gel (Blågel, Cefar, Malmö, Sweden). Charcoal-filtered and humidified air passed over the antennal preparation through a 
glass tube outlet connecting to the GC transfer line, which was heated at $255^{\circ} \mathrm{C}$. The temperature of the $\mathrm{GC}$ oven was programmed from $80^{\circ} \mathrm{C}$ for $1 \mathrm{~min}$, then at $10^{\circ} \mathrm{C} / \mathrm{min}$ to $210^{\circ} \mathrm{C}$, held for $10 \mathrm{~min}$ and then to $230^{\circ} \mathrm{C}$ at $10^{\circ} \mathrm{C} / \mathrm{min}$ and held for another $10 \mathrm{~min}$. For SPME samples, the fiber was inserted into the GC inlet and held for $5 \mathrm{~min}$. Data were analyzed with the software GC-EAD Pro Version 4.1 (Syntech, Kirchzarten, Germany).

Gas Chromatography/Mass Spectrometry An Agilent 5975 mass-selective detector coupled to an Agilent 6890 gas chromatograph was used to analyze the pheromone gland extracts, SPME samples, and the fatty acyl pheromone biosynthetic precursors. An HP-INNOWax column (as above), and a non-polar column HP-5MS $(30 \mathrm{~m} \times 0.25 \mathrm{~mm}$ i.d., and $0.25 \mu \mathrm{m}$ film thickness; J\&W Scientific, USA) were used. Carrier gas was helium at a constant flow of $0.8 \mathrm{ml} / \mathrm{min}$ corresponding to linear velocity of $33 \mathrm{~cm} / \mathrm{s}$. For analysis of most samples, the oven temperature was programmed as in the GC/EAD analysis. However, to separate better the Z5-14:Ald and E5-14:Ald isomers, a slower oven temperature program was set with the HP-INNOWax column as $60^{\circ} \mathrm{C}$ for $1 \mathrm{~min}$, then at $4{ }^{\circ} \mathrm{C} / \mathrm{min}$ to $200{ }^{\circ} \mathrm{C}$, and then to $230^{\circ} \mathrm{C}$ at $10^{\circ} \mathrm{C} / \mathrm{min}$ and held for $15 \mathrm{~min}$. For the analysis of DMDS-adducts of methanolized fatty acyl precursors, the HP-5MS column was used, and the oven temperature was programmed from $80{ }^{\circ} \mathrm{C}$ for $2 \mathrm{~min}$, then at $15^{\circ} \mathrm{C} / \mathrm{min}$ to $140^{\circ} \mathrm{C}$, and then to $260^{\circ} \mathrm{C}$ at $5^{\circ} \mathrm{C} / \mathrm{min}$ and held for $20 \mathrm{~min}$.

Compounds were identified based on comparison of their retention times and mass spectra with those of synthetic references on both polar and non-polar columns. Double bond positions in the fatty acyl biosynthetic precursors were localized by GC/MS analysis of the dimethyldisulphide adducts of corresponding methyl esters, prepared according to Dunkelblum et al. (1985).

Field Experiments Field trapping experiments were carried out from $22^{\text {th }}$ March to $7^{\text {th }}$ May 2013 in the Opdenhorst farm $\left(33^{\circ} 43^{\prime} \mathrm{S} 18^{\circ} 58^{\prime} \mathrm{E}\right)$ in the Paarl district (disclaimer: this farm was not particularly more affected than any nearby estate, whether table grape or wine farm.). Synthetic blends prepared in various dose and composition in hexane were loaded on rubber septa (Catalogue no. 224100-020, Wheaton Science Products, Millville, NJ, USA) as lures. Butylated hydroxytoluene (BHT, $0.02 \%$ ) was added to the hexane as antioxidant to extend the field life of the aldehydes.

Treatments including a negative control with hexane alone were evaluated in two experiments. The first experiment was designed to determine the optimal dosage of a ternary blend containing all the three identified GC/EAD active components, Z5-14:Ald, Z7-14:Ald, and Z9-16:Ald (baits A-D). The blend ratio was set as found in the SPME collection, i.e., $33: 100: 12$, respectively. The second experiment (baits
F-H) was designed to include treatments with one component subtracted at the second highest dosage used in the first group. For each treatment there were five replicates. A positive control (bait C) was used in both groups to allow comparison between groups. The actual blend ratios in all the treatments were confirmed by GC/FID analysis on an HP-INNOWax column before the field test.

Delta-traps with pheromone lures and sticky inserts (Csalomon, Budapest, Hungary) were suspended just below the vine canopy and spaced $15 \mathrm{~m}$ apart in two rows also $15 \mathrm{~m}$ apart in five sites, each at least $100 \mathrm{~m}$ apart, with the pheromone treatments in random sequences. Traps were inspected once a week and redistributed within each replicate so as to minimize the potential position effect. The trapped moths were identified by their morphological characteristics.

Statistical Analyses Differences in trap catch between treatments were compared using one-way ANOVA analysis on log $(\mathrm{x}+1)$ transformed data, followed by a Least Significant Difference (LSD) test $(P<0.01)$. All analyses were performed using SPSS ver.16.

\section{Results}

Pheromone Identification Analysis of the hexane extracts of female abdominal tips from $H$. capensis by GC/EAD did not reveal any EAD-active peaks. As an alternative approach, SPME proved to be highly effective for the collection of the pheromone from live female adults, even when sampling from a small number of individuals. GC/EAD analyses of the SPME samples showed clearly that the male antennae responded to three components in the collections from conspecific females (Fig. 1). Compounds 1 and 2 eluted close to each other in relatively large amounts and elicited large antennal responses, whereas compound 3 was present in much smaller amounts and evoked a smaller antennal response. These active components were considered as potential pheromone components and identified by GC/MS analysis.

The mass spectrum of the most abundant compound 2 showed a tentative molecular ion at $m / z 210$, a fragment of $[\mathrm{M}-18]^{+}$at $\mathrm{m} / \mathrm{z} 192$, and a relatively less abundant fragment of $[\mathrm{M}-44]^{+}$at $m / z 166$. These diagnostic ions suggested a possible structure of a mono-unsaturated $\mathrm{C}_{14}$ aliphatic aldehyde (Fig. 2). Compared to component 2, the mass spectrum of component 1 exhibited the same fragments, except for the missing molecular ion at $\mathrm{m} / \mathrm{z} 210$. However, the ion ratios were very different between the two spectra, implying that the two components might have similar structures but different double bond locations. The ions at $\mathrm{m} / \mathrm{z} 166$ and $\mathrm{m} / \mathrm{z} 98$ were particularly prominent in the spectrum of compound 1 (Fig. 2), and the latter fragment was previously reported as a 


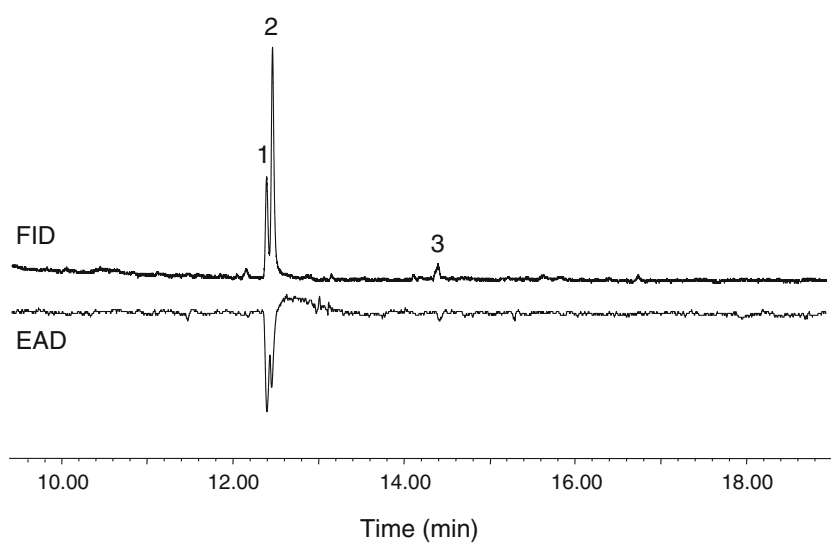

Fig. 1 Coupled gas chromatographic-electroantennographic analysis of volatiles from female Holocacista capensis collected by SPME. The upper trace is the chromatogram monitored with flame ionization detector (FID), and the lower trace is the antennal response from conspecific male antennae. The SPME sample was collected for $24 \mathrm{hr}$ from 8 virgin females at age of 4-5 d-old

diagnostic ion in the 5,7- and 7,9- conjugated hexadecadienyl compounds (Nishida et al. 2003).

As it was not possible to perform DMDS derivatization directly on the SPME collections, we analyzed potential fatty acyl biosynthetic precursors extracted from the abdominal tips and subjected to basic methanolysis. GC/MS analyses of the methyl esters showed in addition to the ubiquitous fatty acids myristic, palmitic, palmitoleic, stearic, oleic, linoleic, and linolenic acids, two mono-unsaturated $\mathrm{C}_{14}$ acids (Fig. 3a, b). GC/MS analysis of the DMDS adducts of the methyl esters revealed two $\mathrm{C}_{14}$ methyl esters exhibiting double bonds in different positions. One compound had a double bond between carbon atoms 5 and 6 in the acyl skeleton, as indicated by a pair of diagnostic ions at $m / z 161 / 173$, and a molecular ion at $m / z$ 334. In the other compound, the double bond was between carbon atoms 7 and 8 , as indicated by the ion pair at $\mathrm{m} / \mathrm{z} 189 / 145$, and a molecular ion at $\mathrm{m} / \mathrm{z} 334$ (Fig. 3c). These two esters were identified as methyl (Z)-5-tetradecenoate (Z514:Me) and methyl (Z)-7-tetradecenoate (Z7-14:Me) by comparing their mass spectra and retention times with those of the reference compounds. These results suggested that the monounsaturated $\mathrm{C}_{14}$ aldehydes in the SPME samples should have a double bond at 5 - and 7-positions, respectively. These structures were verified by comparing the mass spectra and GC retention times of the insect-derived compounds with corresponding data for synthetic Z5-14:Ald and Z7-14:Ald, and

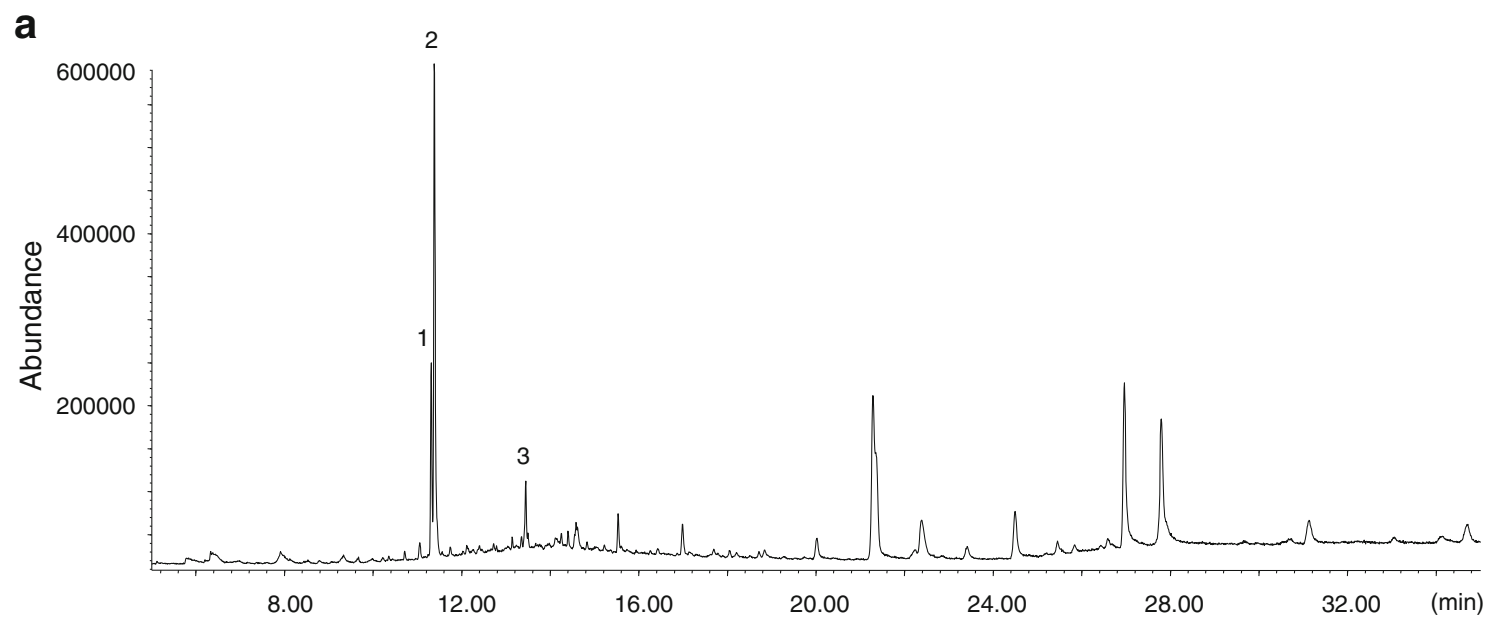

b
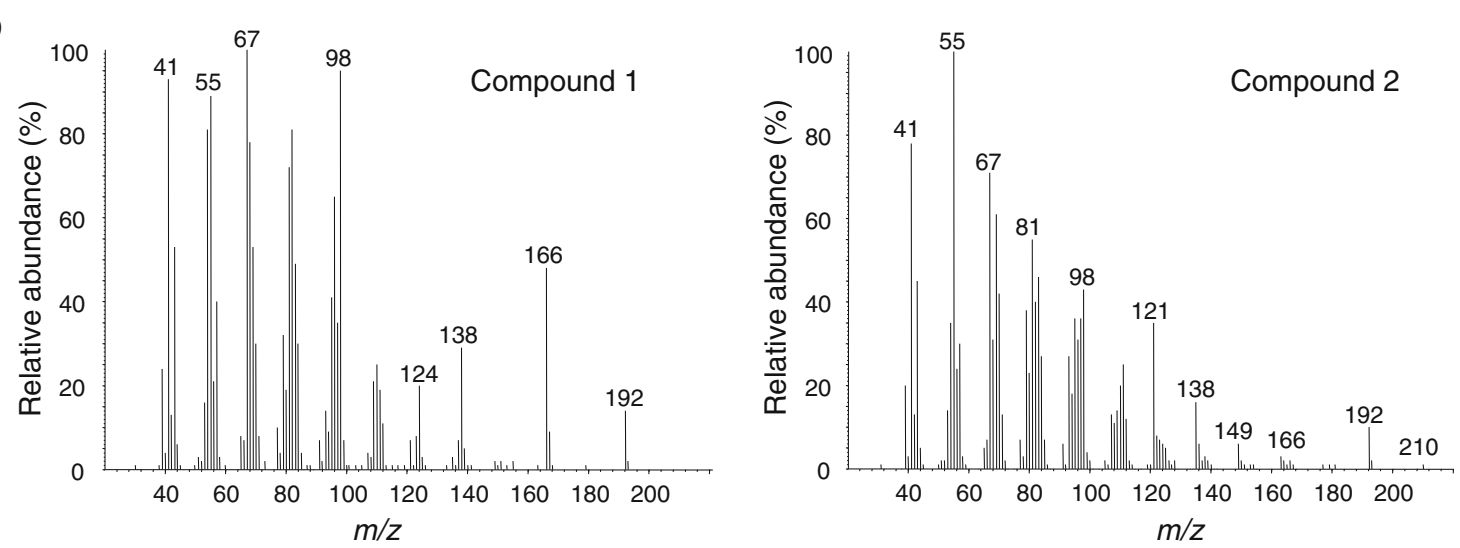

Fig. 2 GC/MS analysis of SPME collection from female Holocacista capensis. (a) total ion current (TIC) chromatogram. The SPME sample was collected for $48 \mathrm{hr}$ from 9 virgin females at age of 2-4 d-old. (b) mass spectra of GC/EAD-active compounds 1 and 2 
a

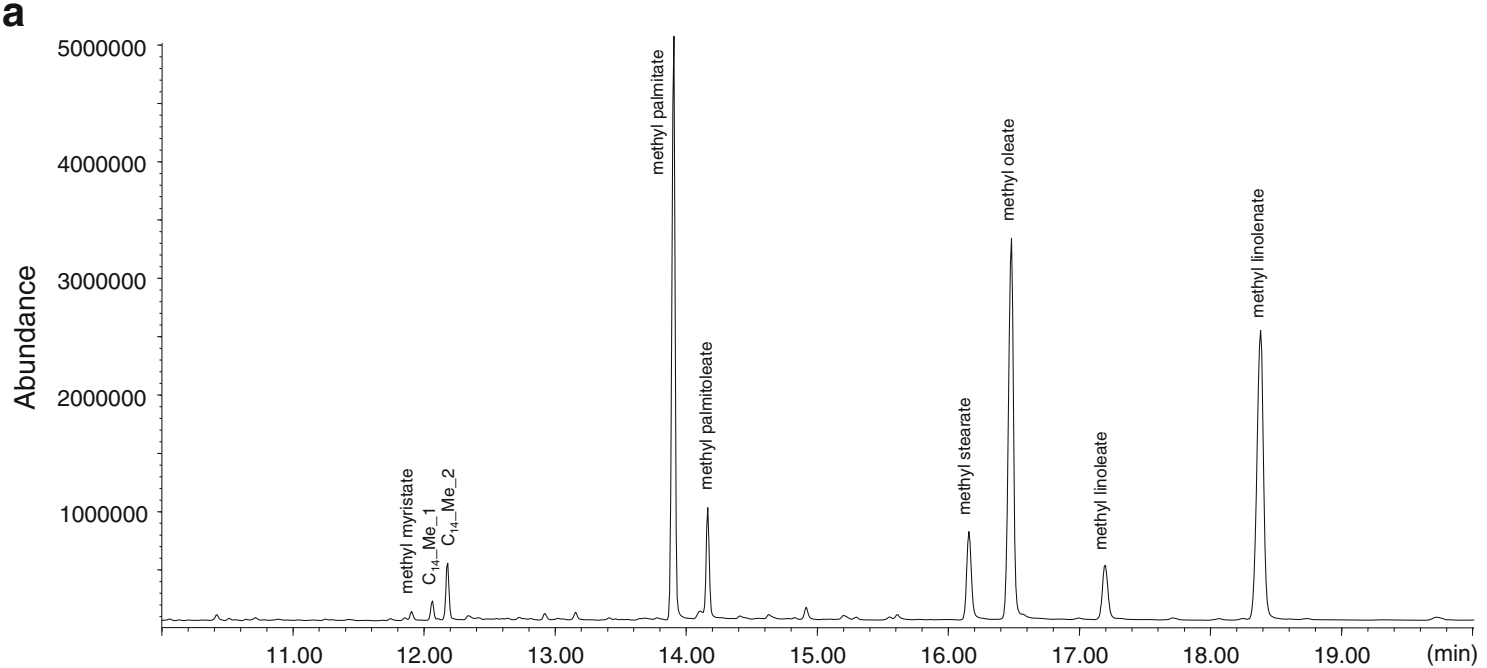

b

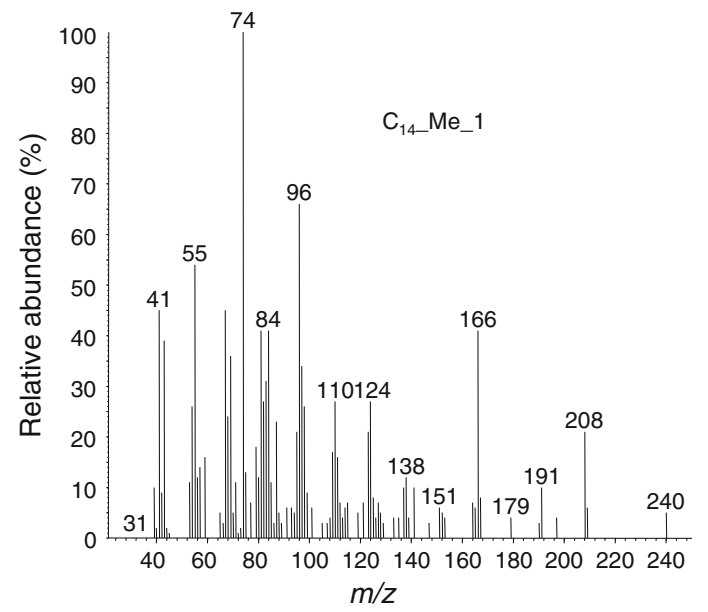

C

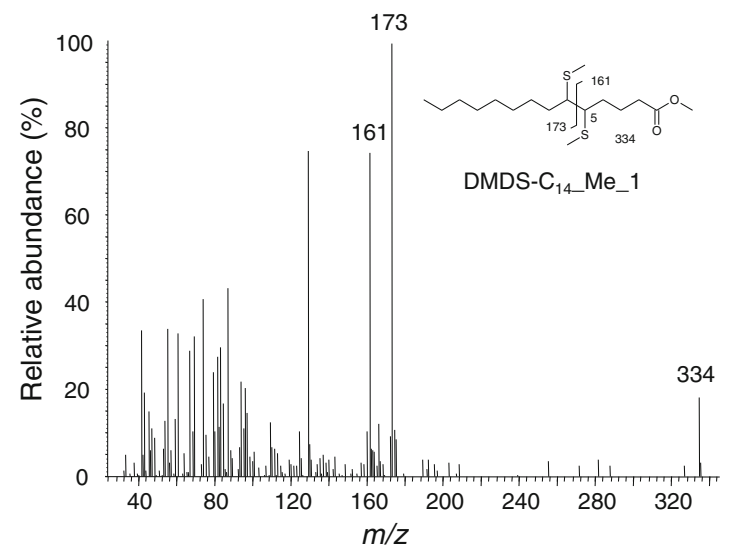

Fig. 3 GC/MS analysis of pheromone fatty acyl biosynthetic precursors from pheromone glands of Holocacista capensis in form of their methyl esters. (a) total ion current (TIC) chromatogram of gland fatty acyl methyl

their geometric isomers E5-14:Ald and E7-14:Ald. The position and configuration of the double bond was confirmed as $\mathrm{Z} 5$ in compound 1 and $\mathrm{Z} 7$ in compound 2.

The mass spectrum of component 3 showed a putative molecular ion at $m / z 238$, a fragment of [M-18] at $m / z 220$,
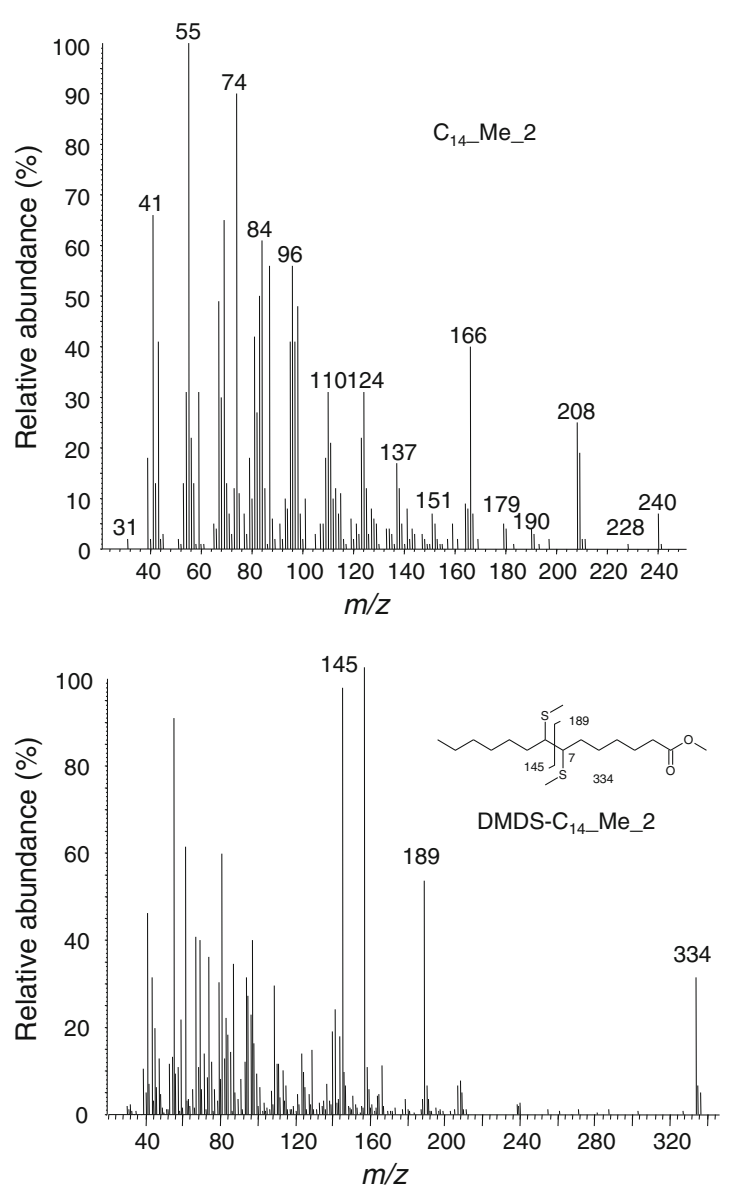

esters; (b) mass spectra of the two $\mathrm{C}_{14}$ mono-unsaturated methyl esters; (c) mass spectra of DMDS-adducts showing a double bond at 5- and 7position in the $\mathrm{C}_{14} \_\mathrm{Me} \_1$ and $\mathrm{C}_{14} \_\mathrm{Me}$ _2, respectively

and a fragment of $[\mathrm{M}-44]^{+}$at $\mathrm{m} / \mathrm{z} 194$, indicating a monounsaturated $\mathrm{C}_{16}$ aldehyde. Correspondingly, $\mathrm{a}_{16}$ monounsaturated acid was found from the DMDS adducts of the fatty acid methyl esters. The related mass spectrum exhibited a pair of diagnostic ions at $\mathrm{m} / \mathrm{z} 145 / 217$ and a molecular ion at $\mathrm{m} / \mathrm{z}$ 
Fig. 4 Trap catches of male Holocacista capensis by different dosages and blends of candidate pheromone components in a table grape vineyard in Stellenbosch, South Africa. Bars with the same letters indicate means that are not significantly different at $P<0.01$, one-way-ANOVA on $\log (\mathrm{x}+1)$ transformed data followed by a LSD test; 5 replicates for each treatment
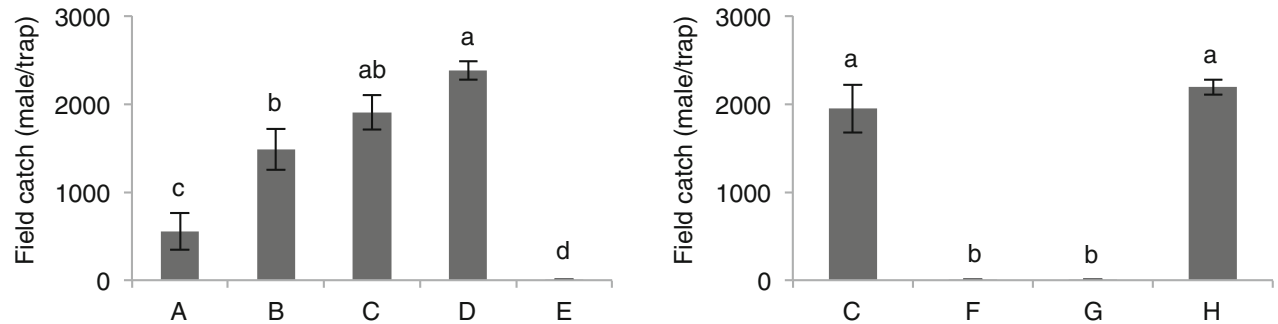

$\begin{array}{llllll}\text { ( } \mu \text { g/bait) } & & & & & \\ \text { Z5-14:Ald } & 3.3 & 10 & 33 & 99 & 0 \\ \text { Z7-14:Ald } & 10 & 30 & 100 & 300 & 0 \\ \text { Z9-16:Ald } & 1.2 & 3.6 & 12 & 36 & 0\end{array}$

$\begin{array}{lllll}\text { ( } \mu \mathrm{g} / \mathrm{bait}) & & & & \\ \text { Z5-14:Ald } & 33 & 0 & 33 & 33 \\ \text { Z7-14:Ald } & 100 & 100 & 0 & 100 \\ \text { Z9-16:Ald } & 12 & 12 & 12 & 0\end{array}$

362, thus indicating a double bond between carbon atoms 9 and 10. Consequently, compound 3 in the SPME samples was identified as Z9-16:Ald by comparing the mass spectrum and retention time of the natural product with corresponding data of synthetic $(E)-9-$ hexadecenal and Z9-16:Ald on two columns.

The amounts of the three EAD-active components, 1, 2, and 3, obtained in SPME collections were estimated as 1.1, 2.9 , and $0.4 \mathrm{ng}$, respectively, based on the comparison of the peak area with the reference compounds of known concentration. The synthetic Z5-14:Ald, Z7-14:Ald and Z9-16:Ald elicited strong responses from the antennae of male $H$. capensis in $\mathrm{GC} / \mathrm{EAD}$ analyses.

Field Tests To test the behavioral activity of the pheromone candidates, field-trapping experiments were carried out in a plantation with table grapes in South Africa. In the first experiment, the blend of Z5-14:Ald, Z7-14:Ald, and Z9-16:Ald at
$33+100+12 \mu \mathrm{g} / \mathrm{bait}$ in the ratio found in the SPME samples, was more attractive to $H$. capensis males than the lower doses, and equally good as the three times higher dose. In the second experiment, the binary blend of Z5-14:Ald and Z7-14:Ald in a ratio of 1:3 was as attractive as the ternary bland to male H. capensis, whereas subtraction of either Z5-14:Ald or Z714:Ald from the ternary blend decreased the trap catch, indicating that both tetradecenals are essential to the attractiveness (Fig. 4). This two-component sex pheromone was highly effective in attracting $H$. capensis. In the case of the optimized blend and dose (treatment H in Fig. 4), more than 2000 males/ trap were caught in the first week of the field experiment.

\section{Discussion}

We identified the sex pheromone of $H$. capensis as a binary blend of Z5-14:Ald and Z7-14:Ald. The combination of
Fig. 5 Differentiation of lepidopteran sex pheromones based on chemical structures. Phylogeny of early lepidopteran superfamilies with estimated time of divergence is retrieved from Regier et al. $(2013,2015)$ and Wahlberg et al. (2013). Type I pheromone refers to the longchain fatty alcohols, aldehydes, and acetates. Type II pheromone refers to the $\mathrm{C}_{17}-\mathrm{C}_{23}$ polyenes and corresponding epoxides. For the sake of simplicity, the new monotypic families Aenigmatineidae and Tridentaformidae are left out. The Palaephatidae are paraphyletic with regard to Tischerioidea (Regier et al. 2015)

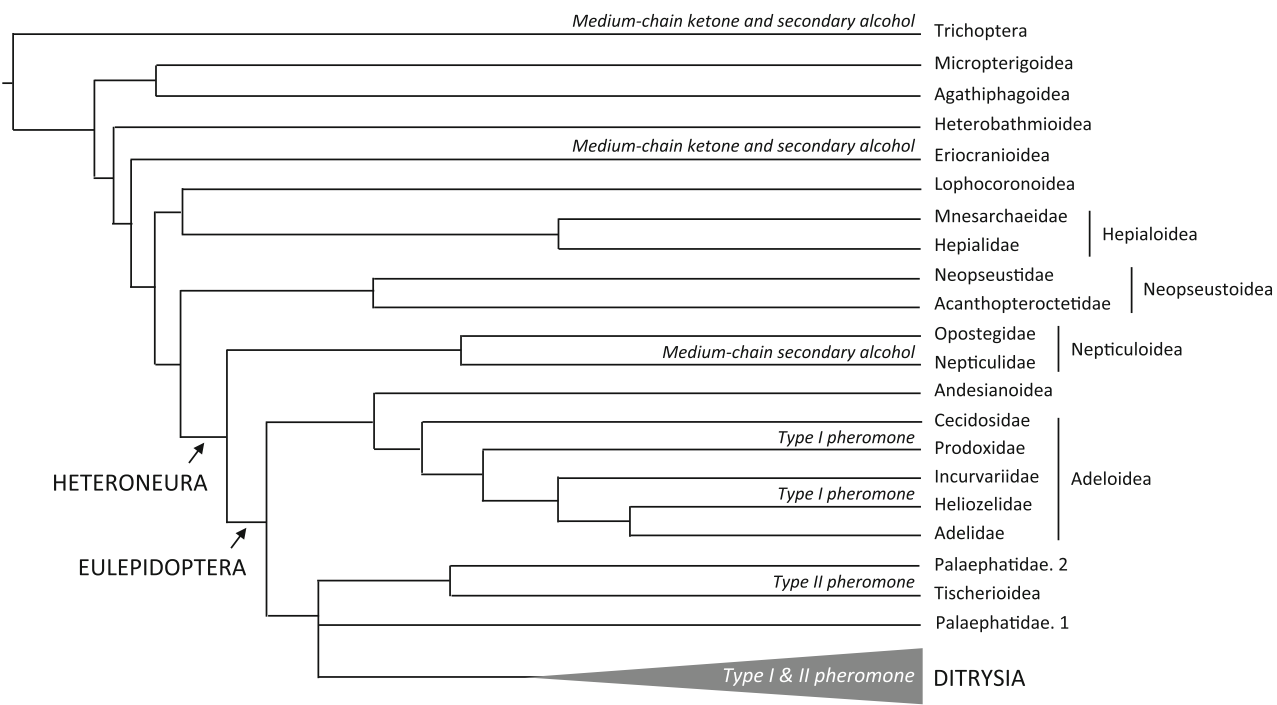

\begin{tabular}{|c|c|c|c|c|}
\hline Triassic & Jurassic & Cretaceous & Cenozoic & \\
\hline 200 & 150 & 100 & 50 & 0 \\
\hline
\end{tabular}


SPME, GC/EAD, and GC/MS proved to be effective for the collection and identification of the sex pheromones from small heliozelid moths.

According to the Pherobase (www.pherobase.com including original references), Z7-14:Ald was identified previously as a sex pheromone component in some Prays species belonging to the relatively primitive ditrysian moth family Praydidae (Yponomeutoidea). It also was attractive to a few noctuid species, such as Spaelotis clandestina (Harris) and Simyra henrici (Grote) (Steck et al. 1982a, b). As previously mentioned, Z7-14:Ald was recorded as an attractant for a heliozelid species Antispila treitschkiella in a field screening experiment using synthetic lepidopteran pheromone compounds (Tóth et al. 1992). Compared to Z7-14:Ald, Z5-14:Ald has not been reported as a moth pheromone component, although it was reported as sex attractant to the noctuid moth Agrotis volubilis Harvey in a field survey, in which a set of $\mathrm{C}_{12}, \mathrm{C}_{14}$ and $\mathrm{C}_{16}$ straight olefinic aldehydes and aldehyde-acetate mixtures were used as candidate lures (Underhill et al. 1977).

In this study, solvent extracts of the pheromone glands did not contain the pheromone components but SPME collections did. As a strategy to avoid the potential cell toxicity caused by the accumulation of the reactive aldehydes, the females might release the compounds immediately after their biosynthesis. It also is possible that the time for dissecting the female abdominal tips in this study was not optimal, due to the lack of knowledge about the exact pheromone-releasing period in $H$. capensis. The relative amounts of the three components observed in SPME collections were not necessarily the actual ratios present in the pheromone gland or even those released from the gland, due to the probable different affinities of the compounds and the fiber. In the present study, the $\mathrm{C}_{14}$ and $\mathrm{C}_{16}$ monoene aldehydes would be expected to differ significantly in their affinities for the fiber, whereas discrimination between the two $\mathrm{C}_{14}$ aldehyde isomers, Z5-14:Ald and Z7-14:Ald, would be much less because of their close physicochemical properties.

The two methyl esters, Z7-14:Me and Z5-14:Me found in the pheromone gland extracts after methanolysis of fatty acyl pheromone precursors may be derived by limited chainshortening ( $\beta$-oxidation) of palmitoleic acid $((Z)-9$ hexadecenoic acid) and oleic acid ((Z)-9-octadecenoic acid), respectively. This proposed pathway is in agreement with what has been confirmed for the predominant type I pheromones, i.e., long-chain fatty alcohols and corresponding aldehydes and acetates, in higher lepidopteran species. It remains to be investigated whether the desaturase involved in this pathway belongs to the ubiquitous metabolic $\Delta 9$ desaturases, which produce palmitoleic and oleic acids, or the Lepidoptera-specific $\Delta 9$ desaturase subfamily that is exclusively used for pheromone production (Liénard et al. 2008). An alternative, less parsimonious pathway, requiring two unusual desaturases directly acting at the 7- and 5-positions of myristate, cannot be positively excluded without performing the appropriate experiments.
Heliozelid moths belong to the superfamily Adeloidea (formerly Incurvarioidea), which are among the lepidopteran lineages that diverged before the origin of the Ditrysia to which more than $98 \%$ of Lepidoptera belong (Fig. 5) (van Nieukerken et al. 2011; Regier et al. 2015). The currently known female-produced sex pheromones found in the non-ditrysian moths fall into three distinct types according to their chemical characteristics. One type, found in the adeloid species, e.g., Lampronia capitella (Clerck), family Prodoxidae (Löfstedt et al. 2004), and H. capensis, family Heliozelidae (current study), comprise unsaturated fatty alcohols, aldehydes, and acetates, which are typical so called Type I moth pheromones (Ando et al. 2004). The longchain polyenes of the tischeriid Tischeria ekebladella (Bjerkander) (Molnár et al. 2012) are structurally similar to the Type II pheromones identified in the Ditrysia (Millar 2000). The third type consists of chiral, medium-chain secondary alcohols and their corresponding ketones. These pheromones are found in some nepticulid species, e.g., Stigmella malella (Stainton) and Trifurcula melanoptera van Nieukerken \& Puplesis (Tóth et al. 1995), and in the even earlier diverging lineage Eriocranioidea (Zhu et al. 1995) as well as in the caddisflies from the sister order Trichoptera (Löfstedt and Kozlov 1997). According to recent phylogenetic studies (Regier et al. 2013, 2015; Wahlberg et al. 2013), the Tischeriidae form together with the Palaephatidae the sister group of the Ditrysia, whereas the Adeloidea and Andesianoidea are sister groups to the above combination (Fig. 5). The Nepticuloidea branch off just before the Adeloidea, and have the primitive pheromone type, suggesting that the common sex pheromones of the extant ditrysian moths might have evolved in the stemgroup of Adeloidea/Andesianoidea and remaining Lepidoptera. Identification of a sex pheromone from a species in Andesianoidea, the sister group to the Adeloidea, in such a case would be interesting and possibly corroborate this suggestion.

The highly attractive pheromone lure for $H$. capensis reported in this study will be useful to perform monitoring and large-scale control of this secondary vineyard pest. Furthermore, identification of the pheromone of this primitive moth species provides further insight into the early evolutionary history of lepidopteran pheromones.

Acknowledgments We are grateful to Silvia Richter for assisting with collecting the leafminers, and Hein Carstens, the owner of the Opdenhorst farm, for allowing us to set up field trapping experiments in his orchards. We thank Niklas Wahlberg for comments on the phylogenetic hypothesis. This work was partly supported by the Birgit och Sven Håkan Olssons stiftelse to CL and HLW, and by the South African Table Grape Industry (SATI) to all authors.

Open Access This article is distributed under the terms of the Creative Commons Attribution 4.0 International License (http://creativecommons.org/licenses/by/4.0/), which permits unrestricted use, distribution, and reproduction in any medium, provided you give appropriate credit to the original author(s) and the source, provide a link to the Creative Commons license, and indicate if changes were made. 


\section{References}

Alma A (1995) Bio-ethologic and epidemiologic researches on Holocacista rivillei Stainton (Lepidoptera Heliozelidae). Redia 78:373-378

Ando T, Inomata S-I, Yamamoto M (2004) Lepidopteran sex pheromones. In: Schulz S (ed) The chemistry of pheromones and other semiochemicals I: topics in current chemistry, vol 239. Springer, Berlin, Heidelberg, New York, pp 51-96

Andrey D, Amstutz R (2000) Determination of pesticide residues in "organic" wines on the Swiss market. Mitt Lebensm Hyg 91:300-305

Bernardo U, van Nieukerken EJ, Sasso R, Gebiola M, Gualtieri L, Viggiani G (2015) Characterization, distribution, biology and impact on Italian walnut orchards of the invasive North-American leafminer Coptodisca lucifluella (Lepidoptera: Heliozelidae). Bull Entomol Res 105:210-224

Bjostad LB, Roelofs WL (1984) Sex pheromone biosynthetic precursors in Bombyx mori. Insect Biochem 14:275-278

Borg-Karlson A-K, Mozûraitis R (1996) Solid phase micro extraction technique used for collecting semiochemicals. identification of volatiles released by individual signalling Phyllonorycter sylvella moths. Z Naturforsch C 51:599-602

Cabras P, Garau VL, Pirisi FM, Cubeddu M, Cabitza F, Spanedda L (1995) Fate of some insecticides from vine to wine. J Agric Food Chem 43:2613-2615

Corey EJ, Suggs JW (1975) Pyridinium chlorochromate. An efficient reagent for oxidation of primary and secondary alcohols to carbonyl compounds. Tetrahedron Lett 16:2647-2650

Dunkelblum E, Tan SH, Silk PJ (1985) Double-bond location in monounsaturated fatty acids by dimethyl disulfide derivatization and mass spectrometry: Application to analysis of fatty acids in pheromone glands of four Lepidoptera. J Chem Ecol 11:265-277

Duso C, Pozzebon A, Baldessari M, Angeli G (2011) Current status of grapevine leafminers in North-eastern Italy. IOBC-WPRS Bull 67: 203-206

Heppner JB, Dixon WN (1995) Potential spread of Phyllocnistis citrella (Lepidoptera: Gracillariidae) in the United States. Am Entomol 41: $110-114$

Kozlov M, Zhu J, Philipp P, Francke W, Zvereva E, Hansson B, Löfstedt C (1996) Pheromone specificity in Eriocrania semipurpurella (Stephens) and E. sangii (Wood) (Lepidoptera: Eriocraniidae) based on chirality of semiochemicals. J Chem Ecol 22:431-454

Liénard MA, Strandh M, Hedenström E, Johansson T, Löfstedt C (2008) Key biosynthetic gene subfamily recruited for pheromone production prior to the extensive radiation of Lepidoptera. BMC Evol Biol 8(270):1-15. doi:10.1186/1471-2148-8-270

Löfstedt C, Kozlov M (1997) A phylogenetic analysis of pheromone communication in primitive moths. In: Cardé RT, Minks AK (eds) Insect pheromone research, new directions. Chapman \& Hall, New York, pp 473-489

Löfstedt C, Zhu J, Kozlov MV, Buda V, Jirle EV, Hellqvist S, Löfqvist J, Plass E, Franke S, Francke W (2004) Identification of the sex pheromone of the currant shoot borer Lampronia capitella. J Chem Ecol 30:643-658

Maier C (2001) Exotic Lepidopteran leafminers in North American apple orchards: rise to prominence, management, and future threats. Biol Invasions 3:283-293

Millar JG (2000) Polyene hydrocarbons and epoxides: a second major class of lepidopteran sex attractant pheromones. Annu Rev Entomol 45:575-604

Minarro M, Jacas JA (2011) Pest status of leafminers in cider-apples: the case of orchards in Asturias (NW Spain). Crop Prot 30:1485-1491

Molnár BP, Tröger A, Toshova TB, Subchev M, van Nieukerken EJ, Koster JCS, Szőcs G, Tóth M, Francke W (2012) Identification of the female-produced sex pheromone of Tischeria ekebladella, an oak leafmining moth. J Chem Ecol 38:1298-1305

Nishida T, Vang LV, Yamazawa H, Yoshida R, Naka H, Tsuchida K, Ando T (2003) Synthesis and characterization of hexadecadienyl compounds with a conjugated diene system, sex pheromone of the persimmon fruit moth and related compounds. Biosci Biotechnol Biochem 67:822-829

Regier JC, Mitter C, Zwick A, Bazinet AL, Cummings MP, Kawahara AY, Sohn J-C, Zwickl DJ, Cho S, Davis DR, Baixeras J, Brown J, Parr C, Weller S, Lees DC, Mitter KT (2013) A large-scale, higher-level, molecular phylogenetic study of the insect order Lepidoptera (moths and butterflies). PLoS ONE 8:e58568. doi:10.1371/journal.pone.0058568

Regier JC, Mitter C, Kristensen NP, Davis DR, van Nieukerken EJ, Rota J, Simonsen TJ, Mitter KT, Kawahara AY, Yen S-H, Cummings MP, Zwick A (2015) A molecular phylogeny for the oldest (nonditrysian) lineages of extant Lepidoptera, with implications for classification, comparative morphology and life history evolution. Syst Entomol. doi:10.1111/syen.12129

Steck WF, Underhill EW, Bailey BK, Chisholm MD (1982a) Z)-7tetradecenal, a seasonally dependent sex pheromone of the wmarked cutworm, Spaelotis clandestina (Harris) (Lepidoptera: Noctuidae. Environ Entomol 11:1119-1122

Steck WF, Underhill EW, Chisholm MD (1982b) Structure-activity relationships in sex attractants for North American noctuid moth. J Chem Ecol 8:731-754

Tóth M, Szöcs G, Sziráki G, Sauter W (1992) Sex attractants for male Microlepidoptera found in field trapping tests in Hungary. J Appl Entomol 113:342-355

Tóth M, Szőcs G, van Nieukerken EJ, Philipp P, Schmidt F, Francke W (1995) Novel type of sex pheromone structure identified from Stigmella malella (Stainton) (Lepidoptera: Nepticulidae). J Chem Ecol 21:13-27

Ueno W, Hayasaka T, Endo S, Shibahasi T (1987) Ecology and control of Antispila sp. (Lepidoptera: Heliozelidae) infesting grape leaves. Bull Yamagata Hortic Exp Sta 6:1-18

Underhill EW, Chisholm MD, Steck W (1977) Olefinic aldehydes as constituents of sex attractants for noctuid moths. Environ Entomol 6:333-337

van Nieukerken EJ, Geertsema H (2015) A new leafminer on grapevine and Rhoicissus (Vitaceae) in South Africa within an expanded generic concept of Holocacista (Insecta, Lepidoptera: Heliozelidae). ZooKeys 507:41-97

van Nieukerken EJ, Kaila L, Kitching IJ, Kristensen NP, Lees DC, Minet J, Mitter C, Mutanen M, Regier JC, Simonsen TJ and others (2011) Order Lepidoptera Linnaeus, 1758. In: Zhang Z-Q (ed.), Animal biodiversity: An outline of higher-level classification and survey of taxonomic richness. Zootaxa 3148:212-221

van Nieukerken EJ, Wagner DL, Baldessari M, Mazzon L, Angeli G, Girolami V, Duso C, Doorenweerd C (2012) Antispila oinophylla new species (Lepidoptera, Heliozelidae), a new North American grapevine leafminer invading Italian vineyards: taxonomy, DNA barcodes and life cycle. ZooKeys 170:29-77

Wahlberg N, Wheat CW, Peña C (2013) Timing and patterns in the taxonomic diversification of Lepidoptera (butterflies and moths). PLoS ONE 8:e80875. doi:10.1371/journal.pone.0080875

Wang HL, Zhao CH, Millar JG, Cardé RT, Löfstedt C (2010) Biosynthesis of unusual moth pheromone components involves two different pathways in the Navel Orangeworm, Amyelois transitella. J Chem Ecol 36:535-547

Zhu J, Kozlov M, Philipp P, Francke W, Löfstedt C (1995) Identification of a novel moth sex pheromone in Eriocrania cicatricella (Zett.) (Lepidoptera: Eriocraniidae) and its phylogenetic implications. J Chem Ecol 21:29-43 